\title{
Chapter 6 \\ Supramolecular Structures as Carrier Systems Enabling the Use of Metal Ions in Antibacterial Therapy
}

\author{
J. Natkaniec, Anna Jagusiak, Joanna Rybarska, Tomasz Gosiewski, \\ Jolanta Kaszuba-Zwoińska, and Malgorzata Bulanda
}

\begin{abstract}
The antimicrobial activity of metal ions, especially silver ions, has been known since ancient times. Consequently, finding an accessible, cheap and efficient carrier of metal ions remains an important challenge in molecular biology. The supramolecular system presented in this chapter consists of a mixture of Congo red and Titan yellow molecules forming a supramolecular ligand which is a potent complexing agent of silver ions. Delivery of ions in complex with supramolecular dye is advantageous due to the reduced toxicity. In addition, the use of Congo red provides selective action and - thanks to increased solubility - facilitates efficient dispersion of the carrier dye and excretion from the organism.
\end{abstract}

Keywords Supramolecular compounds • Congo red • Titan yellow • Silver ions • Microorganisms $\bullet$ Antimicrobial activity $\bullet$ Antifungal activity

The original version of this chapter was revised.

An erratum to this chapter can be found at https://doi.org/10.1007/978-3-319-65639-7_8

J. Natkaniec • T. Gosiewski • M. Bulanda

Department of Molecular Medical Microbiology, Chair of Microbiology,

Jagiellonian University - Medical College, Krakow, Poland

e-mail: joanna.natkaniec@uj.edu.pl; tomasz.gosiewski@uj.edu.pl; malgorzata.bulanda@uj.edu.pl
A. Jagusiak $(\bowtie) \cdot J$. Rybarska
Chair of Medical Biochemistry, Jagiellonian University - Medical College,
Kopernika 7, 31-034, Krakow, Poland
e-mail: anna.jagusiak@uj.edu.pl; mbstylin@cyf-kr.edu.pl
J. Kaszuba-Zwoińska
Department of Pathophysiology, Jagiellonian University - Medical College,
Czysta 18, 31-121, Krakow, Poland
e-mail: jolanta.kaszuba-zwoinska@uj.edu.pl 


\subsection{Introduction}

The increasing antibiotic resistance of microorganisms is one of the greatest global health problems, as recalled by the World Health Organization [1, 2]. The percentage of multi-drug resistant isolates or isolates resistant to commonly used antibiotics is increasing throughout Europe. Actinobacter baumani, Pseudomonas aeruginosa and Enterobacteriaceae are included in the top three "critical" pathogens which have MDR (Multi-Drug Resistance). They are causing severe, frequently deadly infections and there is a critical need for new drugs to combat these pathogens [3-5]. In 2016, most strains - among Gram negative species Enterobacteriacae (such as: Klebsiella pneumoniae or Escherichia coli) that were also resistant to the third generation of cephalosporins, fluoroquinolones and aminoglycosides - have been reported in southern and southeastern Europe [6]. Methicillin-resistant Staphylococcus aureus (MRSA) is no longer just a hospital treatment problem, as in many parts of the world, including Europe, the number of MRSA infections (community-associated MRSA, CA-MRSA) is increasing. In Europe, eight out of 30 countries have reported having MRSA indexes exceeding $25 \%$ [6]. One of the causes of this problem is the high use of antibiotics, which increased significantly in the years 2010-2014 in the European Community, although it did not look the same in all countries. For example, in 2014, the number of antibiotics administered outside hospital treatments in Greece was more than three times higher than in the Netherlands (10.6 DDD (defined daily dose) per 1000 inhabitants per day in the Netherlands to 34.1 DDD per 1000 inhabitants per day in Greece) [7]. Unfortunately, the mere supervising of alarm strains, their registration, as well as the control system of antibiotic consumption are insufficient in the fight against microbial multi-resistance and searching for alternative means to solve the problem becomes necessary.

Among many propositions of solutions we will find e.g.: applying the so-called combined therapy, which uses two or more antibiotics administered simultaneously or combines the action of two different drugs in one molecule [8]. A promising alternative is the combination of chemotherapeutics with heavy metal ions, for example: silver, which has been known for its bactericidal properties since ancient times $[9,10]$. The ideal situation would be to use silver compounds to increase the antibacterial effectiveness of commonly known and used antibiotics. However, in order for silver ions to be selective, they must be bound to a suitable carrier that would allow them to be precisely delivered and, in addition, would allow a more effective bacteriostatic/bactericidal effect when coacting with the antibiotic.

Finding an easily accessible, cheap and efficient carrier is one of the most important challenges researchers are facing $[11,12]$. The carrier system presented here consists of a mixed supramolecular system of CR, which binds TY, which is a strong complexing agent for silver ions, by means of intercalation. The use of metal ions in the form of complexes makes it possible to lower the toxicity threshold. On the other hand, using a carrier system provides selectivity of action and, by increased solubility, facilitates excretion from the organism. 


\subsection{Silver Complexes with TY in the Supramolecular CR System}

Supramolecularity is the phenomenon of the occurrence of organic compounds in the form of multimolecular systems resulting from the association of single molecules [13]. The classic example of a supramolecular system is CR (Fig. 6.1A). CR-type compounds associate creating elongated ribbon-like structures. Systems produced this way demonstrate the ability to bind different guest organic compounds by means of intercalation and, consequently, are characterized by various activities resulting from the nature of introduced components. Properly selecting the elements for such a complex system allows e.g. to increase its polarity and solubility, reduce cell entry and facilitate excretion, which further lowers the toxicity of components carried by the supramolecular system [14-16]. Supramolecular CR interacts with proteins, although it is an atypical ligand, which binds outside the active group of the protein [17-20]. There are also reports of bacteria interacting with CR [21-23].

Silver is an example of an antibacterial metal, commonly used locally, mainly as metallic silver (nanosilver, colloidal silver). Delivering silver as complexed ions using a carrier increases the safety of therapies using this metal. CR, however, has a low affinity for binding metals, including silver, hence the search for other compounds that form metal ion complexes with high efficiency. These compounds should interact directly with proteins, or indirectly through interaction with CR. One of the compounds which partially fulfils these parameters is TY (TY or DY9) (Fig. 6.1B) [24, 25]. TY poorly interacts with proteins compared to CR. It however creates strong complexes with CR, which can thus be used as a carrier system for both TY and its complex with silver ions. The TY molecule is symmetrical and planar, although its symmetry is disturbed by the central bond [26]. Similarly to CR, TY has a non-polar central benzene ring and polar sulphonic groups located at the poles of the molecule. This kind of structure allows for the self-association of individual molecules leading to the formation of complex supramolecular systems. A triazene bond is located at the centre of the TY molecule. This feature affects the

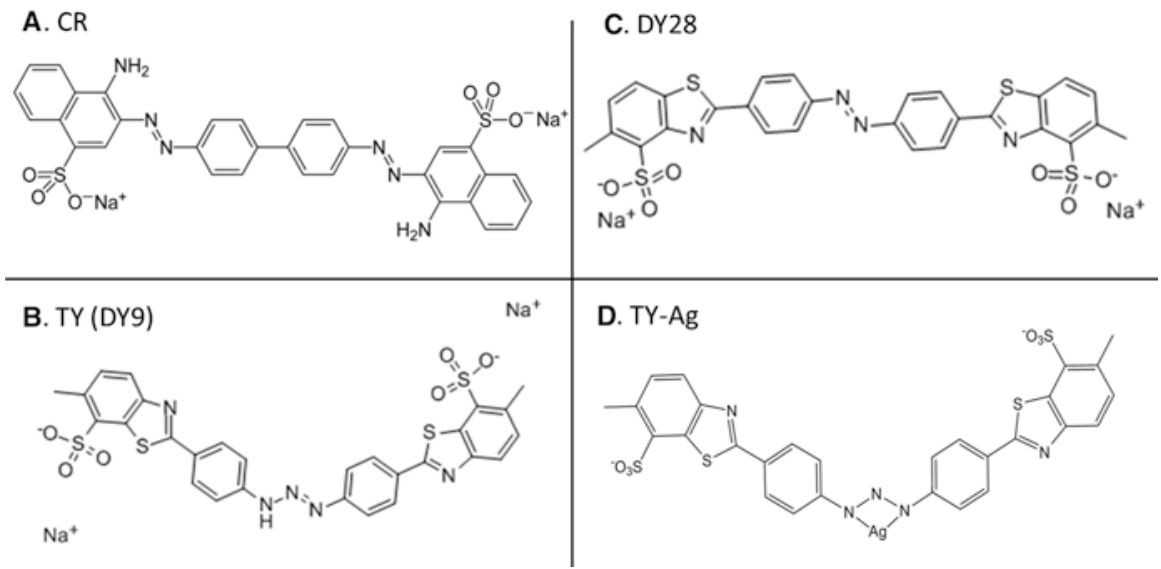

Fig. 6.1 Structural formulas: (A) CR; (B) TY; (C) DY 28; (D) TY-silver ions complex 
spatial structure of TY, which is different than in the case of CR. The triazene moiety is involved in the formation of TY complexes with silver ions (Fig. 6.1D), as demonstrated by using the TY analogue - DY 28 which, instead of the triazole bond, has a diazo bond and does not form complexes with $\mathrm{Ag}^{+}$ions (Fig. 6.1C).

The complexation of silver ions by TY was demonstrated by spectral analysis, and independently by using sodium dithionite to reduce ternary CR/TY/ $\mathrm{Ag}^{+}$complexes previously subjected to electrophoresis. As a result of reduction CR was decomposed and discoloured (because the azo bonds were reduced), the TY stain remained unchanged (as the triazene bond was not reduced), while silver appeared in the form of dark spots both within the TY/ $\mathrm{Ag}^{+}$complex and the CR/TY/ $/ \mathrm{gg}^{+}$ complex (both migrating towards the anode) as well as in the form of the excess migrating towards the cathode [24].

Silver ions are bound by TY in a molar ratio of 1:0.8, as demonstrated by titration of TY with silver (Fig. 6.2).

The strength of silver ions - TY interaction was evaluated by spectral analysis of the stability of the complexes in the presence of anions present in physiological solutions $\left(\mathrm{Br}^{-}, \mathrm{PO}_{4}^{-}, \mathrm{Cl}^{-}, \mathrm{CNS}^{-}\right)$. Complexing silver ions increases the reactivity threshold of silver practically only for -SH groups, which are present on the surface of bacteria, because silver reactivity in complexes is reduced. The dissociation constant of the complex was estimated to be approx. $10^{-13}$, because the anions with $\mathrm{Kd}$ values $<10^{-13}$ did not displace silver from the complex [25].

The viscosity of the TY/ $\mathrm{Ag}^{+}$complex was evaluated using viscometric analysis the analysis of solution sedimentation in time, depending on composition. Viscosity

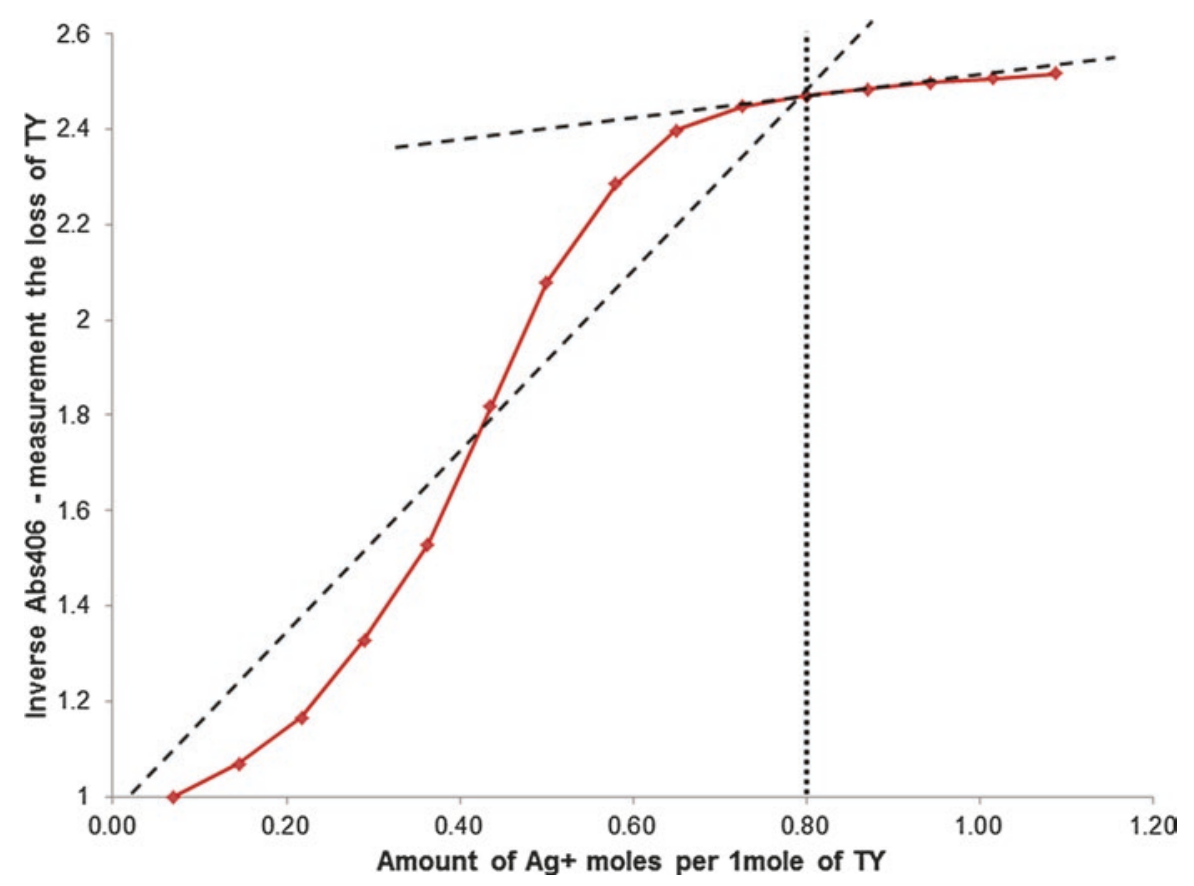

Fig. 6.2 Effect of titration of Titan yellow (TY) with silver $\left(\mathrm{Ag}^{+}\right)$. The optimal molar ratio of TY: $\mathrm{Ag}^{+}$is 1:0.8 


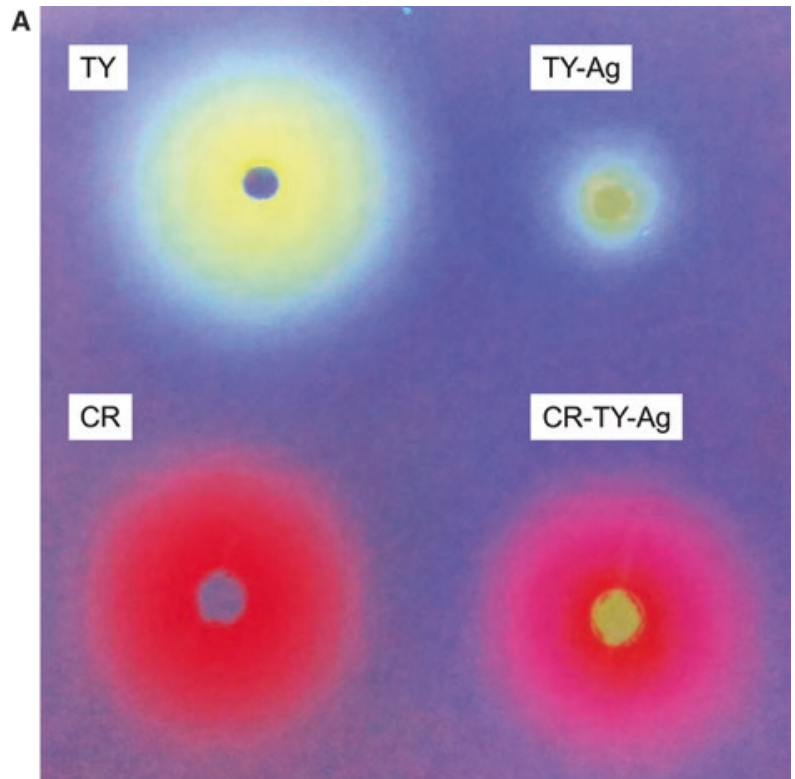

B<smiles></smiles>

Fig. 6.3 (A) Comparison of diffusion rates in agarose gel: TY, CR, TY/ $/ \mathrm{Ag}^{+}$and $\mathrm{CR} / \mathrm{TY} / \mathrm{Ag}^{+} \mathrm{com}-$ plexes after $24 \mathrm{~h}-$ a significant slowdown of the TY/ $\mathrm{Ag}^{+}$complex diffusion due to increased viscosity of the complex results from the cross-linking of TY molecules by silver ion (B)

increases with the addition of an increasing amount of silver, hence the conclusion that silver cross-links TY molecules (Fig. 6.3B).

These results were confirmed in a diffusion test, which compared the diffusion of TY, CR as well as TY/ $\mathrm{Ag}^{+}$and CR/TY/ $\mathrm{Ag}^{+}$complexes in agarose gel over $24 \mathrm{~h}$. The 
results have shown, that the $\mathrm{TY} / \mathrm{Ag}^{+}$complex practically does not diffuse (diffusion zone diameter of $8 \mathrm{~mm}$ ), and when bound to $\mathrm{CR}$, the diameter of the diffusion zone is $18 \mathrm{~mm}$ and is close to the free TY (diffusion zone diameter of $20 \mathrm{~mm}$ ) and free CR (diffusion zone diameter of $22 \mathrm{~mm}$ ). This shows the important role of CR in increasing the solubility of the TY/Ag ${ }^{+}$complex (Fig. 6.3A).

Since the diffusion zone in the $\mathrm{CR} / \mathrm{TY} / \mathrm{Ag}^{+}$complex is $18 \mathrm{~mm}$ and is $4 \mathrm{~mm}$ smaller than the diffusion zone of free CR (which equals $22 \mathrm{~mm}$ ), we conclude that the TY/ $\mathrm{Ag}^{+}$complex is bound by $\mathrm{CR}$. TY interacts with $\mathrm{CR}$ by intercalation into the ribbon structure of $\mathrm{CR}$. The presence of $\mathrm{CR}$ in the $\mathrm{CR} / \mathrm{TY} / \mathrm{Ag}^{+}$complex reduces the viscosity of the complex, at the same time increasing its solubility. Additionally, the presence of CR may extend the range of TY activity by binding to certain bacteria [21-23]. Both TY and CR are carrying negative charges, yet they manage to interact and create stable complexes. This was confirmed in studies using electrophoretic and spectrophotometric methods [24, 25]. The results of electrophoresis on agarose gel show the formation of CR and TY complexes at an increasing CR to TY molar ratio. At two and five times molar excess of TY over CR (CR/TY4 and CR/TY5 samples) it was observed that the complex migrating quicker than free $\mathrm{CR}$ was formed and no excess of CR was observed. At 1:1 molar ratio and 2- and 5-fold excess of CR (CR/ TY3, CR/TY2 and CR/TY1 samples), a smear of free CR was observed. Comparison of the migration speed of free TY with all the samples containing complexes (line A) indicates the presence of complexes in all five samples migrating at the same rate, as opposed to samples containing analogous amounts of free TY migrating at different rates (Fig. 6.4). The presence of $\mathrm{Ag}^{+}$complexed with $\mathrm{TY}$ increases the $\mathrm{CR}$ binding capability, because even at molar ratios of $\mathrm{CR}$ to the $\mathrm{TY} / \mathrm{Ag}^{+}$complex equal to 5:1 and 2:1 (CR/TY/Ag1 and CR/TY/Ag2 samples) there is no free, unbound CR, as it was in the case of CR/TY complexes without silver (Fig. 6.5).

A distinct change in the absorption spectrum of TY after binding silver ions was observed (Fig. 6.6).

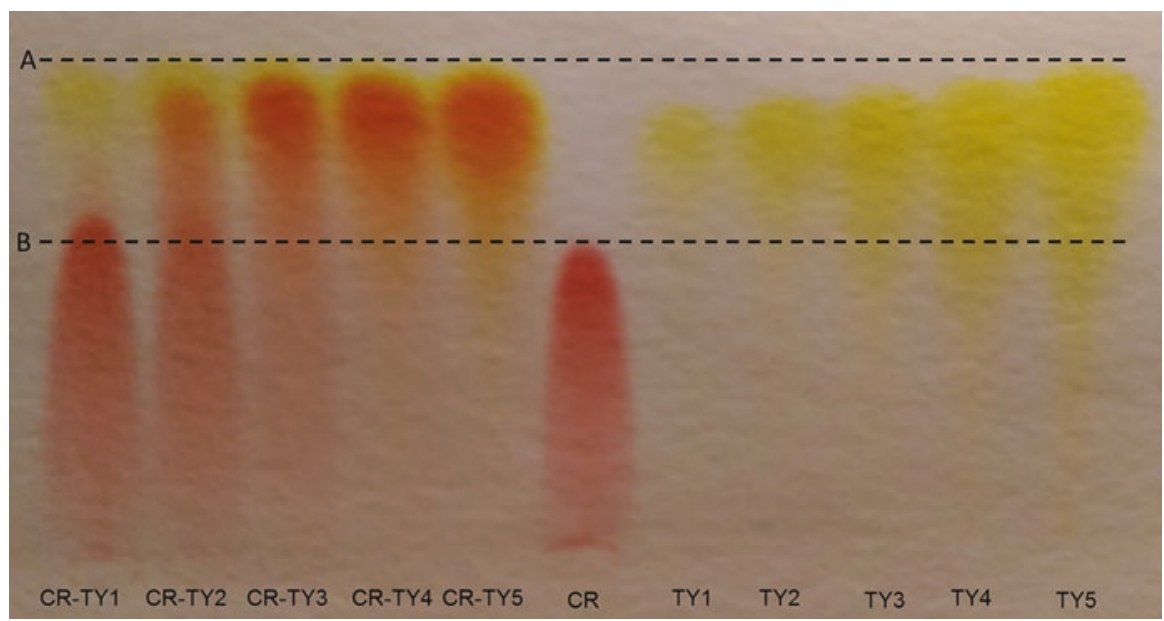

Fig. 6.4 Agarose gel electrophoresis of CR/TY molar ratio: CR/TY1 - 5:1; CR/TY2 - 2:1; CR/ TY3 - 1:1; CR/TY4 - 1:2; CR/TY5 - 1:5; CR (equivalent to molar ratio 1:1); TY-Titan yellow; Molar ratio equivalents: TY1 - 5:1; TY2 - 2:1; TY3 - 1:1; TY4 - 1:2; TY5 - 1:5 


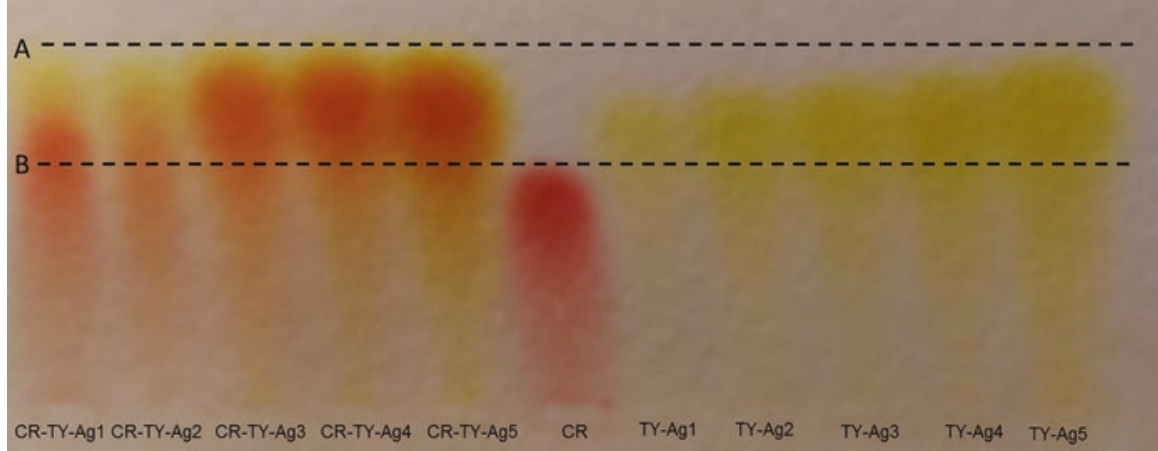

Fig. 6.5 Agarose gel electrophoresis of CR/TY/Ag ${ }^{+}$molar ratio: CR/TY/Ag1 - 5:1; CR/TY/ Ag2 - 2:1; CR/TY/Ag3 - 1:1; CR/TY/Ag4 - 1:2; CR/TY/Ag5 - 1:5; CR-Congo red (equivalent to molar ratio 1:1); TY/Ag ${ }^{+}$; Molar ratio equivalents: TY/Ag1 - 5:1; TY/Ag2 - 2:1; TY/Ag3 - 1:1; TY/Ag4 - 1:2
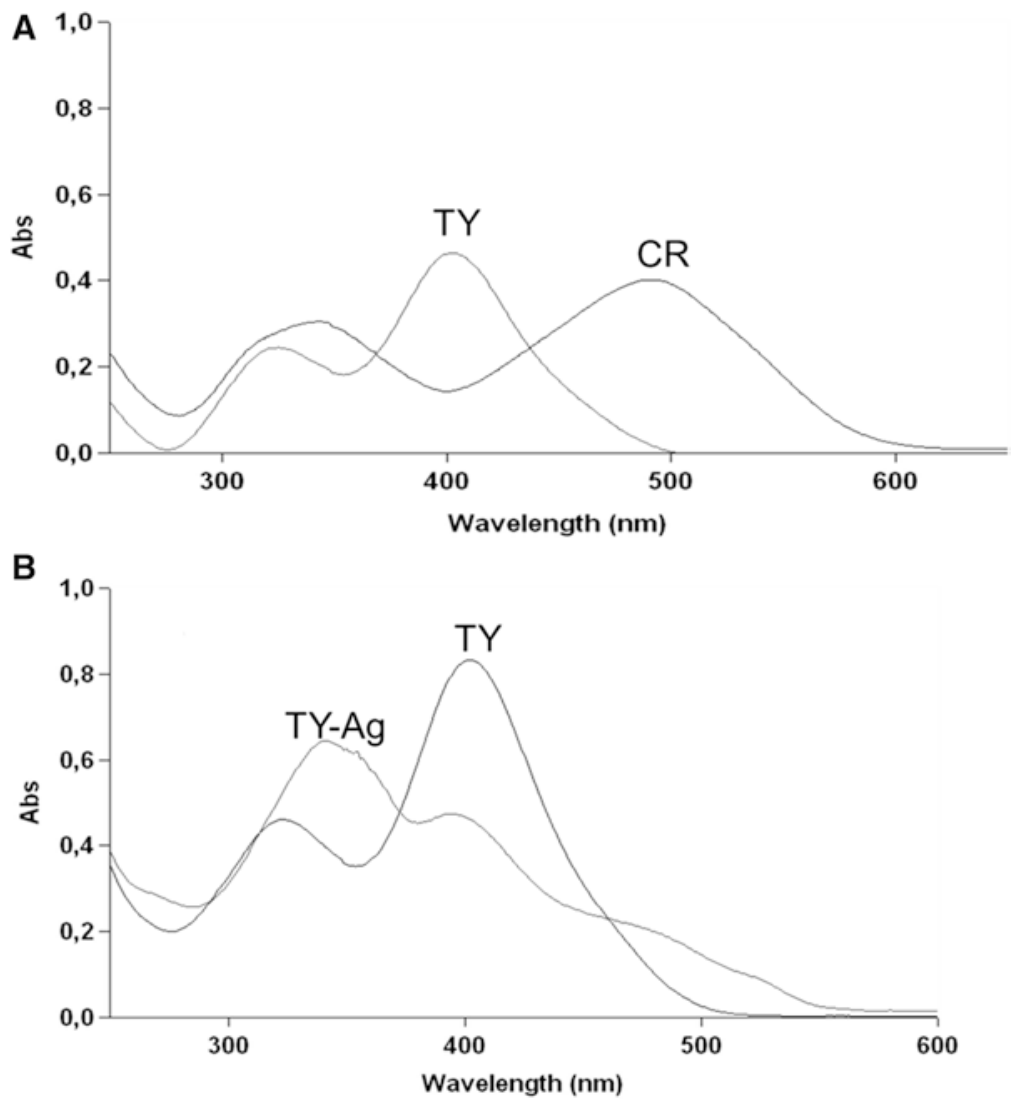

Fig. 6.6 Absorption spectra: (A) $\mathrm{CR}$ and TY; (B) TY and TY/Ag ${ }^{+}$ 


\subsection{Antimicrobial and Antifungal Activity of Silver Ion Complexes with Titan Yellow (TY/Ag+) and TY/Ag ${ }^{+}$ Complexes with Congo Red (CR/TY/Ag')}

TY is a carrier system for silver ions. In the form of a complex it can affect the efficiency of antibiotics, by acting with them and, at the same time, reducing the toxicity of the used silver.

Free $\mathrm{Ag}^{+}$ions demonstrate high antimicrobial activity against Gram-positive and Gram-negative bacteria, fungi and certain viruses [27]. There are also theories regarding the mechanisms which inhibit the actions of silver on bacteria, such as: induction of oxygen free radicals or direct destruction of bacterial cell membranes by silver ions. Silver ions can interact with bacterial cell walls, bacterial capsule, cell membrane proteins, but also penetrate into the cytoplasm [28-30]. Silver ions block the activity of respiratory enzymes in bacterial cells, which prevents cellular respiration. $\mathrm{Ag}^{+}$ions have a high affinity to phosphate groups present in nucleic acids, thus inhibiting the replication of bacterial DNA [31-33]. Uncomplexed silver strongly binds to cell proteins through thiol, amino, carboxyl, imidazole and phosphate groups [34]. Silver, however, after complexation with the carrier, can practically bind only to the -SH groups. It is confirmed by the results presented in Table 6.1, which show a similar reactivity of silver-sensitive bacteria towards silver, as well as towards Ellman's reagent, which is specific for binding thiol groups. The amino acid found in the wall of bacteria susceptible to the activity of silver is cysteine, with a highly reactive -SH group $[35,36]$.

Excessive amount of silver introduced to the body accumulates in the tissues and can lead to necrosis of some organs, such as the liver. The concentration of silver ions over $10 \mathrm{mg} / \mathrm{mL}$ may be toxic for the organism [33], and the wide and uncontrolled use of silver can lead to developing bacterial resistance to silver, as currently is the case of antibiotics. It is therefore justified to search for silver carriers which allow its controlled release and also removal from the body [31].

In the nineteenth century the antiseptic properties of silver against microorganisms (Staphylococcus aureus, Streptococcus, Pseudomonas; Escherichia) were proven [37]. To date, silver nitrate has been shown to be effective against microorganisms of the genus Neisseria and Pseudomonas. The reduction of toxicity of silver used in therapy can be achieved by forming organic complexes. Among commonly known and used complexes are: silver sulfadiazine salt [38, 39] and silver complexes with sulfonamide drugs, which act against Gram-negative and Grampositive bacteria [40]. Colloidal silver or immobilized silver nanoparticles e.g. on silica carriers, are also used. It seems however, that using supramolecular silver carriers is more effective because of the good solubility of the preparation, facilitated excretion and prevention of cell entry leading to the reduced toxicity. The proposed complex of TY with silver $\left(\mathrm{TY} / \mathrm{Ag}^{+}\right)$is just this kind of an organometallic system with possible therapeutic potential and numerous advantages that indicate a chance of its application in medicine. One of the advantages is the use of ionic silver. The application of this complex limits the accumulation of the metal in the 
Table 6.1 Screening of TY, CR, Ellman's Reagent (ER) and the TY/Ag ${ }^{+}$for selected strains comparison with the antibiotic appropriate for the given strain: $A M C$ amoxicillin with clavulanic acid (30 mg); FEP cefepime (30 mg); NY nystatin (100 IU)

\begin{tabular}{|c|c|c|c|c|c|c|c|}
\hline Reference strains & $\begin{array}{l}\overline{\tilde{J}} \\
\bar{z}\end{array}$ & 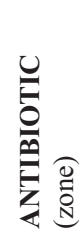 & 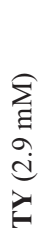 & 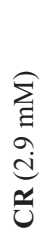 & 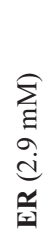 & 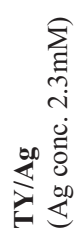 & 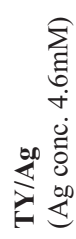 \\
\hline $\begin{array}{c}\text { Staphylococcus } \\
\text { epidermidis ATCC } \\
700296\end{array}$ & $\varnothing$ & $\begin{array}{l}A M C \\
(28)\end{array}$ & $\varnothing$ & $\varnothing$ & $\varnothing$ & 11.4 & 12 \\
\hline $\begin{array}{c}\text { Pseudomonas } \\
\text { aeruginosa ATCC } \\
27853\end{array}$ & $\varnothing$ & $\begin{array}{l}\text { FEP } \\
\text { (26) }\end{array}$ & $\varnothing$ & $\varnothing$ & $\varnothing$ & 10.7 & 11.5 \\
\hline $\begin{array}{c}\text { Pseudomonas } \\
\text { aeruginosa ATCC } \\
33348\end{array}$ & $\varnothing$ & $\begin{array}{l}\text { FEP } \\
\text { (26) }\end{array}$ & $\varnothing$ & $\varnothing$ & $\varnothing$ & 9.3 & 10.7 \\
\hline $\begin{array}{c}\text { Escherichia coli } \\
\text { ATCC } 25922\end{array}$ & $\varnothing$ & $\begin{array}{l}A M C \\
(21)\end{array}$ & $\varnothing$ & $\varnothing$ & $\varnothing$ & 10.5 & 11.3 \\
\hline $\begin{array}{l}\text { Escherichia coli } \\
\text { ATCC } 35218\end{array}$ & $\varnothing$ & $\begin{array}{l}A M C \\
\text { (13) }\end{array}$ & $\varnothing$ & $\varnothing$ & 14 & 9 & 9.5 \\
\hline $\begin{array}{c}\text { Staphylococcus } \\
\text { aureus ATCC } \\
25923\end{array}$ & $\varnothing$ & $\begin{array}{l}A M C \\
(35)\end{array}$ & $\varnothing$ & $\varnothing$ & 21 & 12 & 11 \\
\hline $\begin{array}{c}\text { Staphylococcus } \\
\text { aureus ATCC } \\
29213\end{array}$ & $\varnothing$ & $\begin{array}{l}A M C \\
\text { (18) }\end{array}$ & $\varnothing$ & $\varnothing$ & $\varnothing$ & 8.7 & 10 \\
\hline $\begin{array}{c}\text { Enterococcus } \\
\text { faecalis ATCC } \\
2912\end{array}$ & $\varnothing$ & $\begin{array}{l}A M C \\
(26)\end{array}$ & $\varnothing$ & $\varnothing$ & $\varnothing$ & $\varnothing$ & $\varnothing$ \\
\hline $\begin{array}{c}\text { Streptococcus } \\
\text { agalactiae ATCC } \\
\text { BAA-611 }\end{array}$ & $\varnothing$ & $\begin{array}{l}A M C \\
(26)\end{array}$ & $\varnothing$ & $\varnothing$ & $\varnothing$ & $\varnothing$ & $\varnothing$ \\
\hline $\begin{array}{c}\text { Streptococcus } \\
\text { pyogenes ATCC } \\
700294\end{array}$ & $\varnothing$ & $\begin{array}{l}A M C \\
(32)\end{array}$ & $\varnothing$ & $\varnothing$ & $\varnothing$ & $\varnothing$ & $\varnothing$ \\
\hline $\begin{array}{c}\text { Candida albicans } \\
\text { ATCC } 10231\end{array}$ & $\varnothing$ & $\begin{array}{l}N Y \\
(25)\end{array}$ & $\varnothing$ & $\varnothing$ & $\varnothing$ & 14 & 16 \\
\hline
\end{tabular}

Observation of the size of bacterial inhibition zones $(\mathrm{mm})$ Gray indicates results where the zones were greater than zero 
body, due to the facilitation of excretion in the form of a complex. Complexation of silver reduces its toxicity and allows for its slow release, which prevents the formation of therapeutically disadvantageous silver agglomerates [33]. Interaction between TY and CR creates a possibility of interaction of the ternary TY/CR/ $\mathrm{Ag}^{+}$ system with certain proteins, and also leads to the increased solubility of the complex. Another advantage is the specificity expressed by the reactivity of silver ions towards thiol groups.

\subsubsection{Methodology}

In order to evaluate the effect of silver complexed with TY or with the CR/TY system we have performed screening tests on gram positive and gram negative bacteria and on yeast-like fungi.

The complexes were tested using strains from the collection of the Department of Microbiology of the Jagiellonian University Medical College. In the case of Staphylococcus aureus, Escherichia coli and Pseudomonas aeruginosa, reference strains recommended by EUCAST (European Committee on Antimicrobial Susceptibility Testing) were chosen as control strains for susceptibility testing and as control strains in quality control. These strains are: Staphylococcus aureussubsp. aureus $\left(\mathrm{ATCC}^{\circledR} 29213^{\mathrm{TM}}\right)$, Escherichia coli $\left(\mathrm{ATCC}^{\circledR} 25922^{\mathrm{TM}}\right.$ ) - a susceptible strain that does not possess any antibioticresistance, Escherichia coli $\left(\right.$ ATCC $^{\circledR} 35218^{\mathrm{TM}}$ ) a strain producing TEM-1 $\beta$-lactamase, which causes resistance to all $\beta$-lactam antibiotics, Pseudomonas aeruginosa $\left(\right.$ ATCC $^{\circledR} 27853^{\mathrm{TM}}$ ). Furthermore one strain of Staphylococcus aureussubsp. aureus $\left(\right.$ ATCC $^{\circledR} 25923^{\text {TM }}$ ), which is recommended by CLSI (Clinical \& Laboratory Standards Institute) for susceptibility testing, was chosen.Other reference strains: Staphylococcus epidermidis (ATCC ${ }^{\circledR} 700296^{\mathrm{TM}}$ ), Pseudomonas aeruginosa $\left(\mathrm{ATCC}^{\circledR} 33348^{\mathrm{TM}}{ }^{\text {) }}\right.$, Enterococcus faecalis (ATCC $^{\circledR}$ $2912^{\mathrm{TM}}$ ), Streptococcus agalactiae (ATCC ${ }^{\circledR}$ BAA- $611^{\mathrm{TM}}$ ), Streptococcus pyogenes (ATCC $^{\circledR} 700294^{\mathrm{TM}}$ ), Candida albicans $\left(\right.$ ATCC $^{\circledR} 10231^{\mathrm{TM}}$ ) were selected according to their availability, as were the clinical strains: Pseudomonas aeruginosa (1815), Pseudomonas aeruginosa (18168), Pseudomonas aeruginosa (22726), Escherichia coli (E1), Escherichia coli (E123), Escherichia coli (M243), Staphylococcus aureus (277), Staphylococcus aureus (1934), Staphylococcus aureus (26265).

A diffusion-disk screening method was used to test for antibacterial and antifungal activity by using a filter paper disc impregnated with the tested compound at a specific concentration. It has been assumed that the tested compound will behave similarly to the antibiotic-impregnated disc in the Kirby-Bauer diffusion-disc method, which is used for the determination of drug-susceptibility of microbes. The diffusion process is radial, so a concentration gradient is created. The highest concentration of the tested antibiotic is at the edge of the disc and decreases with the distance. The diameter of the microbial growth inhibition zone is directly proportional to the antibiotic susceptibility, i.e. the greater the growth inhibition zone around the disc, the more the microorganism is susceptible to the given antibiotic. 
Depending on the size of this zone, microbes are defined as: sensitive, medium sensitive or resistant, based on the accepted standards (EUCAST recommendations).

Ten microlitres of the tested compound were applied onto sterile filter paper discs, and then placed on MHA (Mueller-Hinton Agar) media inoculated with bacterial suspension or Sabouraud medium inoculated with fungi suspension (optical density of the suspensions was 0.5 McFarland). The compound diffused into the medium and, if a microbial growth inhibition zone was observed around the disc with a diameter at least $1 \mathrm{~mm}$ greater than the diameter of the disc impregnated with the test compound, it was treated as a positive effect of the tested compound.

First, the control system was tested using free TY without the complexed metal and free CR. On the media, inoculated with the suspension of bacteria or fungi strains prepared in a standard way, were placed two sterile filter paper discs $(\varnothing$, diameter $=5 \mathrm{~mm}$ ) impregnated with $0.9 \% \mathrm{NaCl}$ (control), the tested compound, i.e.: TY $(2.9 \mathrm{mM})$ or CR $(2.9 \mathrm{mM})$ and, additionally, a disc with an antibiotic, selected so to have the widest spectrum of antimicrobial activity possible. As for the strains: amoxicillin with clavulanic acid (AMC) was used at the concentration of $30 \mathrm{mg}$ for S. aureus, E. coli, Enterococcus faecalis,Streptococcus pyogenes,Streptococcus agalactiae; a disc with cefepime at the concentration of $30 \mathrm{mg}$ was used for Pseudomonas aeruginosa; Nystatin was used at the concentration of $100 \mathrm{IU}$ for Candida albicans.

Subsequently, two concentrations of the TY/ $/ \mathrm{gg}^{+}$complex were tested (concentrations of TY: $2.9 \mathrm{mM}$ and $5.75 \mathrm{mM} ; \mathrm{Ag}^{+}$concentrations respectively: $2.3 \mathrm{mM}$ and $4.6 \mathrm{mM}$; molar ratio of TY: $\left.\mathrm{Ag}^{+}=1: 0.8\right)$. The $\mathrm{CR} / \mathrm{TY} / \mathrm{Ag}^{+}$ternary complex was also tested (two concentrations of TY and CR: I. TY: $2.9 \mathrm{mM}$; CR: $2.9 \mathrm{mM}, \mathrm{Ag}^{+}$: $2.3 \mathrm{mM}$; II. TY: $5.75 \mathrm{mM}$; CR: $5.75 \mathrm{mM}, \mathrm{Ag}^{+}: 4.6 \mathrm{mM}$; in both cases the molar ratio of TY: $\mathrm{Ag}^{+}=1: 0.8$; the molar ratio of CR:TY 1:1). Sterile paper discs $(\varnothing=5 \mathrm{~mm})$ were used, impregnated respectively with a filter solution of TY silver complex $\left(\mathrm{TY} / \mathrm{Ag}^{+}\right.$), in two tested concentrations or in a solution of $\mathrm{CR} / \mathrm{TY} / \mathrm{Ag}^{+}$. A disc impregnated with $0.9 \% \mathrm{NaCl}$ was used as control. The discs thus prepared were placed on the MHA medium, inoculated with a bacterial suspension and on a Sabouraud medium, inoculated with a fungi suspension. Microbial suspensions were prepared from reference (Table 6.1) and clinical (Table 6.2) strains and each had an optical density of 0.5 McFarland.

The selective activity of $\mathrm{Ag}^{+}$complexed with $\mathrm{TY}$ or with $\mathrm{CR} / \mathrm{TY}$ was assessed by tests, which consisted of comparing the effects of TY/ $/ \mathrm{g}^{+}$and $\mathrm{CR} / \mathrm{TY} / \mathrm{Ag}^{+}$and the effects of the Ellman reagent (ER). Ellman's reagent is 5,5'-dithiobis (2-nitrobenzoic acid), abbreviated as DTNB - which binds and blocks the thiol groups. The concentration of ER used was $2.9 \mathrm{mM}$, which corresponds to the molar concentration of silver used. The procedure of preparing the microbial suspensions was performed as before. On the inoculated plates with the MHA or Sabourand medium, a control disc impregnated in $0.9 \% \mathrm{NaCl}$, a disc with one of the four aforementioned compounds and a disc with the antibiotic were applied. 
Table 6.2 Results of the screening test of TY, CR, Ellman's Reagent (ER) and TY/Ag+ for selected clinical strains. Shaded cells indicate results with zones above zero

\begin{tabular}{|c|c|c|c|c|c|c|c|}
\hline Clinical strains & $\begin{array}{l}\overline{\tilde{Z}} \\
\bar{Z}\end{array}$ & 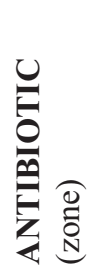 & 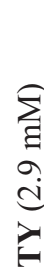 & 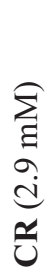 & 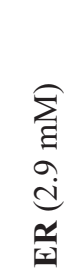 & 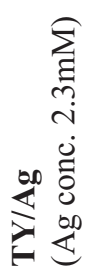 & 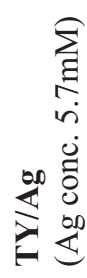 \\
\hline P.aeruginosa 1815 & $\varnothing$ & $\begin{array}{c}\text { FEP } \\
(25)\end{array}$ & $\varnothing$ & $\varnothing$ & $\varnothing$ & 8 & 9 \\
\hline $\begin{array}{c}\text { P. aeruginosa } \\
18168\end{array}$ & $\varnothing$ & $\begin{array}{l}\text { FEP } \\
\text { (15) }\end{array}$ & $\varnothing$ & $\varnothing$ & $\varnothing$ & 8 & 8 \\
\hline $\begin{array}{c}\text { P. aeruginosa } \\
22726\end{array}$ & $\varnothing$ & $\begin{array}{l}\text { FEP } \\
\text { (14) }\end{array}$ & $\varnothing$ & $\varnothing$ & $\varnothing$ & 8 & 10 \\
\hline E.coli E1 & $\varnothing$ & $\begin{array}{c}A M C \\
\text { (24) }\end{array}$ & $\varnothing$ & $\varnothing$ & 13 & 9 & 8 \\
\hline E.coli 123 & $\varnothing$ & $\begin{array}{c}A M C \\
\text { (9) }\end{array}$ & $\varnothing$ & $\varnothing$ & 8 & 6 & 11 \\
\hline E.coli M243 & $\varnothing$ & $\begin{array}{r}A M C \\
\text { (21) }\end{array}$ & $\varnothing$ & $\varnothing$ & 12 & 6 & 6 \\
\hline S.aureus 277 & $\varnothing$ & $\begin{array}{c}A M C \\
\text { (28) }\end{array}$ & $\varnothing$ & $\varnothing$ & 14 & 6 & 10 \\
\hline S.aureus 1934 & $\varnothing$ & $\begin{array}{c}A M C \\
\text { (21) }\end{array}$ & $\varnothing$ & $\varnothing$ & 14 & 10 & 10 \\
\hline S.aureus 26265 & $\varnothing$ & $\begin{array}{c}A M C \\
\text { (20) }\end{array}$ & $\varnothing$ & $\varnothing$ & 14 & 10 & 9 \\
\hline
\end{tabular}




\subsubsection{Results}

In both cases, where free compounds were used: TY and CR did not show growth inhibition zones either in the test strains tested (Table 6.1) or in clinical strains (Table 6.2).

Growth inhibition zones after the application of different concentrations of $\mathrm{Ag}^{+}$ complexed with TY were observed in the case of the strains: S. aureus, E. coli, $S$. epidermidis, $P$. aeruginosa, $C$. albicans. No growth inhibition zones were observed for the strains: E. faecalis, S. agalactiae, S. pyogenes (Tables 6.1 and 6.2). Similar results were obtained for $\mathrm{CR} / \mathrm{TY} / \mathrm{Ag}^{+}$complexes.

Growth inhibitotion zones after applying ER and TY/ $\mathrm{Ag}^{+}$as well as $\mathrm{CR} / \mathrm{TY} / \mathrm{Ag}^{+}$ were observed for the following reference strains: E. coli ATCC 35218 and S. aureus ATCC 25923 (Table 6.1) and in the case of the following clinical strains: E. coli E1; E. coli 123; E. coli 243, S. aureus 277; S. aureus 1934 and S. aureus 26265. Based on these results it can be assumed that complexed silver inhibits these bacterial strains by blocking the thiol groups.

No growth inhibition zones were observed after applying ER, TY/Ag ${ }^{+}$and CR/ TY/Ag ${ }^{+}$in the case of the following standard strains: E. faecalis ATCC 2912, S. agalactiae BAA-611, S. pyogenes ATCC 700294 and in the case of clinical strains: E. fecalis E1; E2; S. agalactie 135, 136, 149; S. pyogenes G0, 282, 287.

In the case of reference strains $S$. epidermidis ATCC 700296, P. aeruginosa ATCC 27853 and ATCC 33348, E. coli ATCC 25922, S. aureus ATCC 29213 and C. albicans ATCC 10231, as well as in the case of the clinical strains: P. aeruginosa $1815,18168,22726$, and for the higher concentrations of $\mathrm{TY} / \mathrm{Ag}^{+}$for $C$. tropicalis, C. parapsilosis i $C$. lusitaniae growth inhibition zones were observed after using complexed $\mathrm{Ag}^{+}$, whereas such zones were not observed after applying ER. Probably, in the case of these strains, silver affects groups other than thiol groups (e.g. amino groups).

In experiments using the $\mathrm{CR} / \mathrm{TY} / \mathrm{Ag}^{+}$complex, there was a tendency to increase the bacterial growth inhibition zone as compared to the experiments, where $\mathrm{Ag}^{+}$was complexed only with TY. This tendency is evident especially when lower concentration of $\mathrm{Ag}$ (2.3 mM) in the CR/TY complex is used. CR significantly reduces the viscosity of the TY/ $\mathrm{Ag}^{+}$complex and improves its diffusion. This result, especially in conjunction with the tendency of CR to interact with certain bacteria, is the basis for recognizing the presented CR/TY system to be an effective silver ion carrier.

\subsection{Determination of the Effect of TY/ $\mathrm{Ag}^{+}$and CR/TY/Ag on Antibiotic Activity on Selected Standard and Clinical Bacterial Strains}

The increasing resistance of bacteria to standard antibiotics limits the possible use of this class of drugs and significantly narrows the therapeutic options. Hence, further studies have tested the possibility of using silver in new, yet unresearched TY/ 
Table 6.3 Observation of the size of growth inhibitory zones $(\mathrm{mm})$

\begin{tabular}{|c|c|c|c|c|c|}
\hline Reference strains & Antibiotic & (1) & (2) & (3) & (4) \\
\hline P. aeruginosaATCC 27853 & FEP & $\varnothing$ & 26 & 11 & 27 \\
\hline S. aureus ATCC 29213 & AMC & $\varnothing$ & 18 & 10 & 28 \\
\hline E. coli ATCC 35218 & AMC & $\varnothing$ & 13 & 11 & 22 \\
\hline
\end{tabular}

(1) Buffer control (sterile discs with a $0.05 \mathrm{M}$ TRIS- $\mathrm{HNO}_{3}$ solution, $\mathrm{pH} 8.2$ ), (2) sterile discs with antibiotics (3) sterile discs with the TY/ $/ \mathrm{Ag}^{+}$solution, and (4) sterile discs with antibiotic with the solution $\left(\mathrm{TY} / \mathrm{Ag}^{+}\right)$

Antibiotics used: $A M C$ amoxicillin with clavulanic acid (30 mg); FEP cefepim (30 mg)

$\mathrm{Ag}^{+}$and $\mathrm{CR} / \mathrm{TY} / \mathrm{Ag}^{+}$complexes as a possible support for antibiotics (an adjuvant system in antibiotic therapy). The effect of analysed silver complexes on antibiotics used for selected strains was tested.

Among the strains that gave a positive response of the growth inhibition zone after applying the TY/ $\mathrm{Ag}^{+}$complex, three strains of standard reference microorganisms were selected for antibody testing: Pseudomonas aeruginosa ATCC 27853, Staphylococcus aureus ATCC 29213 andEscherichia coli ATCC 35218. The study was conducted in accordance with the methodology described above. Sterile filter paper discs (without or with antibiotics) were impregnated using a selected solution: (1) disc without antibiotic impregnated with a $0.05 \mathrm{M}$ TRIS $-\mathrm{HNO}_{3}$ solution, pH 8.2 (buffer control), (2) antibiotic disc, (3) disc without the antibiotic with a solution of the tested compound, and (4) antibiotic disc impregnated with the solution of test compound. The test compound used was: TY- silver ions complex (TY/ $\mathrm{Ag}^{+}$). Then the discs were applied to plates with MHA media inoculated with bacterial suspension.

The studies showed that compounds combined with silver ions ( $\left.\mathrm{TY} / \mathrm{Ag}^{+}\right)$create a growth inhibition zone. It was concluded that silver ions complexed with in TY does not inhibit the action of any of the tested antibiotics used for the analysed bacterial strains. Moreover, when comparing the growth inhibition zones of E. coli and $S$. aureus strains in the presence of antibiotic and the antibiotic combined with the test compound $\left(\mathrm{TY} / \mathrm{Ag}^{+}\right)$, an increase of inhibitory action was observed for the combination. This result shows that silver in the presented complex acts as an adjuvant on the antibiotic used (Table 6.3 and Fig. 6.7). 

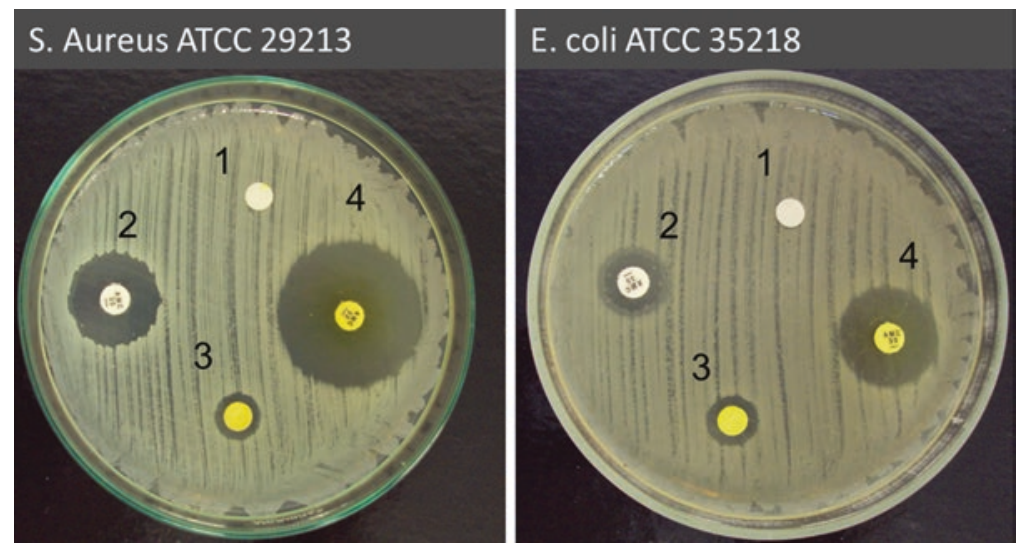

Fig. 6.7 Diameter of growth inhibition zones of S. aureus ATCC 29213 and E. coli ATCC 35218; (1) buffer control (sterile discs impregnated with a sterile 0.05 M TRIS-HNO3 solution, pH 8.2), (2) sterile discs with antibiotic (3) sterile discs impregnated with an TY/ $\mathrm{Ag}^{+}$solution and (4) sterile discs with antibiotic impregnated with the TY/ $\mathrm{Ag}^{+}$solution

\subsection{Cytotoxicity Analysis of the TY/Ag ${ }^{+}$Complex}

Induction of the apoptosis process is one of the main goals of the designed cancer therapies. This is due to the developed mechanisms of cancer cell resistance to programmed death. Therefore, in the next stage of study, the cytotoxicity of the compounds used was analysed by comparing early apoptosis, late apoptosis and necrosis of U937 cells after application of the following concentrations of the TY/Ag ${ }^{+}$complexes: $1 \mu \mathrm{g} / \mathrm{mL} ; 50 \mu \mathrm{g} / \mathrm{mL} ; 200 \mu \mathrm{g} / \mathrm{mL}$ and $400 \mu \mathrm{g} / \mathrm{mL}$ in a $96 \mathrm{~h}$ culture. It was shown that $1 \mu \mathrm{g} / \mathrm{mL}$ and $50 \mu \mathrm{g} / \mathrm{mL}$ concentrations of $\mathrm{TY}$ do not lead to cytotoxic effects in the studied cell line. The concentration of $50 \mu \mathrm{g} / \mathrm{mL}$ of TY/ $\mathrm{Ag}^{+}$results in late apoptosis while concentrations of 200 and $400 \mu \mathrm{g} / \mathrm{mL}$ cause necrosis.

Human U937 lymphoid cell line was obtained from the American Cell Culture Collection (ATCC, Rockville, MD) and cultured in RPMI 1640 medium (GibcoBRL, USA), supplemented with $10 \%$ (v/v) fetal calf serum (Gibco-BRL, USA) heat inactivated, L-glutamine $0.2 \mathrm{M}$ and gentamycin $50 \mu \mathrm{g} / \mathrm{mL}$ (Sigma-Aldrich, Germany) at $37{ }^{\circ} \mathrm{C}$ in a $5 \% \mathrm{CO}_{2}$ incubator of $90 \%$ humidity. Cell viability was monitored by trypan blue exclusion method and counted with a haemocytometer (Fuchs-Rosenthal chamber). The experiments were performed on cells in the logarithmic phase of growth under the condition of $98 \%$ viability, as assessed by trypan blue exclusion. U937 cells were passaged every 4 days. For the experiments U937 cells were seeded into 96-well (Nunck, Denmark) culture plates and grown at density of $0.5 \times 10^{6}$ cells $/ \mathrm{mL}$ in threefold repetition.

$24 \mathrm{~h}$ after cell passage of U937 the cell line cultured at density $0.5 \times 106$ cells/ $\mathrm{mL}, \mathrm{TY}, \mathrm{TY} / \mathrm{Ag}^{+}$or ER reagents suspended in cell culture medium were added to the cell cultures.

The final concentration for TY, TY/ $\mathrm{Ag}^{+}$and ER was $50 \mu \mathrm{g} / \mathrm{ml}$. Cells without any reagent treatment constituted a control group. 
After $72 \mathrm{~h}$ of cell culture duration with the presence of added reagents, U937 cells were harvested by centrifugation at $280 \mathrm{~g}$ for $10 \mathrm{~min}$ and used for flow cytometry analysis.

After 96 h lasting U937 cell cultures, cells were harvested, washed twice with cold PBS (Sigma-Aldrich, Germany) and resuspended in $1 \times$ binding buffer (BD, Pharmingen TM, USA) at a concentration of $1 \times 10^{6}$ cells $/ \mathrm{mL}$. Then, the solution $(100 \mu \mathrm{L})$ was transferred to a 5-mL culture tube, and AnV-APC(AnV-APC, BD, Pharmingen TM, USA) and PI (PI, BD, Pharmingen TM, USA) were added, $5 \mu \mathrm{L}$ each. The cells were vortexed gently and incubated in darkness at room temperature for $15 \mathrm{~min}$. After adding $1 \times$ binding buffer $(400 \mu \mathrm{L})$, the cells were analyzed on a FACS CALIBUR flow cytometer (Becton Dickinson, San Jose, CA) using CellQuest software to calculate the proportion of ADSCs representing various types. Unstained cells, cells stained with AnV-APC alone (for FL-4 fluorescence) and cells stained with PI alone (detected in FL-3) were used as controls to set up compensation and appropriate quadrants. At least 10,000 events were acquired for each sample.

The percentage of apoptotic cells was determined with allophycocyanin (APC) conjugated annexin V. Propidium iodide was used as a standard flow cytometric viability probe to distinguish necrotic cells from viable ones. AnV-APC-positive, PI-negative cells (AnV+PI-) were classified as early apoptotic, AnV-APC- and PIpositive cells (AnV+PI+) as late apoptotic, and AnV-APC-negative, PI-positive cells (AnV-PI+) as necrotic.

Under the experimental conditions, no early apoptotic cells were observed $72 \mathrm{~h}$ after the addition of reagents (Fig. 6.8). No late apoptosis and necrosis were observed in the control cells and the ones treated with the Ellman reagent or free TY. Cells treated with TY/Ag ${ }^{+}$complex showed late apoptotic effects (Fig. 6.9) with a small percentage of necrotic cells (Fig. 6.10). The ability to induce apoptosis in tumor cells by the TY/ $/ \mathrm{Ag}^{+}$complex allows to consider it a promising potential antitumor system.

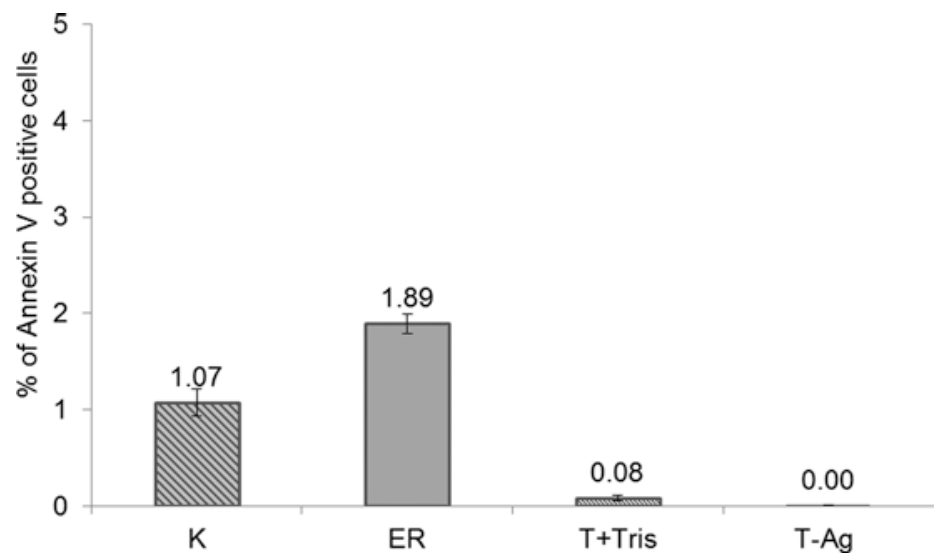

Fig. 6.8. Early apoptosis of U937 cells cultivated in vitro for $72 \mathrm{~h}$ with three different reagents (K - control, ER-Ellmans Reagent $50 \mu \mathrm{g} / \mathrm{mL}$; T + Tris - Titan yellow $50 \mu \mathrm{g} / \mathrm{mL}$ and T- $\mathrm{Ag}^{+}-$Titan yellow $(50 \mu \mathrm{g} / \mathrm{mL})-$ silver ions complex 1:0.8 molar ratio). Data expressed as mean $( \pm \mathrm{SD})$ 


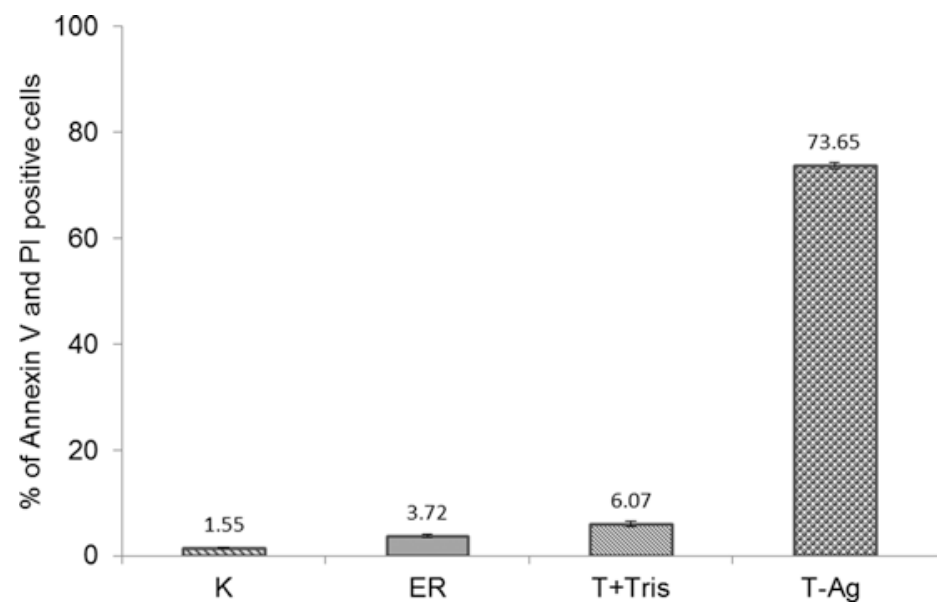

Fig. 6.9 Late apoptosis and necrosis of U937 cells cultivated in vitro for $72 \mathrm{~h}$ with three different reagents $\left(\mathrm{K}\right.$ - control; ER-Ellmans Reagent; $\mathrm{T}+\mathrm{Tris}-\mathrm{Titan}$ yellow and $\mathrm{T}-\mathrm{Ag}^{+}-$Titan yellowsilver ions complex). Data is expressed as mean $( \pm \mathrm{SD})$

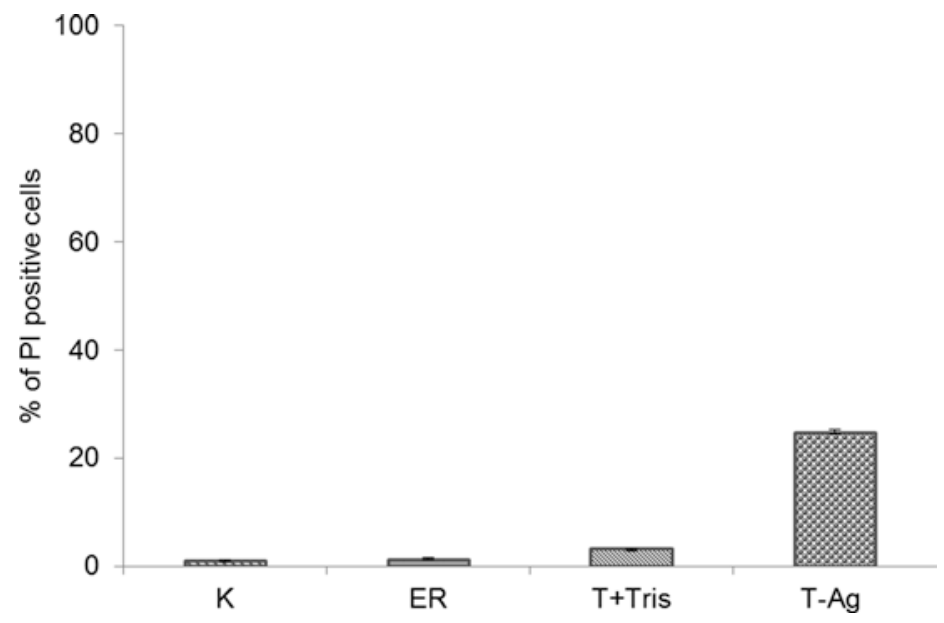

Fig. 6.10 Necrosis of U937 cells cultivated in vitro for $72 \mathrm{~h}$ with three different reagents $(\mathrm{K}-$ control; ER-Ellmans Reagent; T + Tris - Titan yellow and T- $\mathrm{Ag}^{+}-$Titan yellow-silver ions complex); Data is expressed as mean $( \pm \mathrm{SD})$

\subsection{Summary}

The complexes $\mathrm{TY} / \mathrm{Ag}^{+}$and the ternary complex $\mathrm{CR} / \mathrm{TY} / \mathrm{Ag}^{+}$are systems with potentially therapeutic effects. The illustrated carrier systems, thanks to their very good solubility, reduce the accumulation of metal in the body by facilitating the elimination of silver in the form of a complex. Silver complexation reduces toxicity 
and allows to target its action mainly at interactions with thiol groups. Due to the interaction between TY and CR, the TY/CR/ $\mathrm{Ag}^{+}$system can additionally interact with different bacteria. Supramolecular CR protects against cell entry and reduce toxicity of silver ions, while increasing the selectivity of action. Thanks to these features the presented system can be more easily excreted from the body. No toxicity of free TY has been found, however it can induce apoptosis following the complexation of silver ions. Studies conducted on bacterial and fungal strains show that the complex exhibits antimicrobial activity. This is especially valuable in case of resistant bacterial strains that exhibit a significant degree of insensitivity to commonly used antibiotics; using the tested complex increases the extent of action of these antibiotics, consequently allowing them to be used again in the treatment of resistant microorganisms. The obtained results provide the basis for further research on the use of the presented organometallic complex in medicine as an antibacterial agent.

Acknowledgements We acknowledge the financial support from the National Science Centre, Poland (grant no. 2016/21/D/NZ1/02763) and from the project Interdisciplinary PhD Studies "Molecular sciences for medicine" (co-financed by the European Social Fund within the Human Capital Operational Programme) and Ministry of Science and Higher Education (grant no. K/ DSC/001370).

\section{References}

1. WHO (2015) Antibiotic Resistance: Multi-country public awareness survey. ISBN 978924 1509817

2. WHO (2014) Antimicrobial resistance. global Report on Surveillance. ISBN 9789241564748

3. News at a glance Science, 355(6328), 2017, 890-892

4. Taconelli E, Margini N (2017) WHO "Global priority list of antibiotic-resistant bacteria to guide research, discovery, and development of new antibiotics

5. Willyard C (2017) Drug-resistant bacteria ranked. Nature 543(7643):15

6. European Centre for Disease Prevention and Control (2016) Summary of the latest data on antibiotic resistance in the European Union Stockholm: ECDC

7. European Centre for Disease Prevention and Control (2015) Summary of the latest data on antibiotic consumption in the EU Antibiotic consumption in Europe Stockholm: ECDC

8. Wang KK, Stone LK, Lieberman TD et al (2016) A hybrid drug limits resistance by evading the action of the multiple antibiotic resistance pathway. Mol Biol Evol 33(2):492-500

9. Silver S, Phung LT, Silver G (2006) Silver as biocides in burn and wound dressings and bacterial resistance to silver compounds. J Ind Microbiol Biotechnol 33(7):627-634

10. Durán N, Marcato PD, De Conti R et al (2010) Potential use of silver nanoparticles on pathogenic bacteria, their toxicity and possible mechanisms of action. J Braz Chem Soc 21(6):949-959

11. Yang G-W, Gao G-Y, Wang C et al (2008) Controllable deposition of Ag nanoparticles on carbon nanotubes as a catalyst for hydrazine oxidation. Carbon NY 46(5):747-752

12. Guo X, Mei N (2014) Assessment of the toxic potential of graphene family nanomaterials. J Food Drug Anal 22(1):105-115 
13. Skowronek M, Stopa B, Konieczny L et al (1998) Self-assembly of Congo red - a theoretical and experimental approach to identify its supramolecular organization in water and salt solutions. Biopolymers 46(5):267-281

14. Rybarska J, Piekarska B, Stopa B et al (2001) Evidence that supramolecular Congo red is the sole ligation form of this dye for $\mathrm{L}$ chain lambda derived amyloid proteins. Folia Histochem Cytobiol 39(4):307-314

15. Zemanek G, Rybarska J, Stopa B et al (2003) Protein distorsion-derived mechanism of signal discrimination in monocytes revealed using Congo red to stain activated cells. Folia HistochemCytobiol 41(3):113-124

16. Stopa B, Piekarska B, Jagusiak A et al (2011) Acta Biochim Pol 58(Suppl. 2):282. Supramolecular Congo red as a potential drug carrier. Properties of Congo red-doxorubicin complexes in Proceedings of the 2nd Congress of Biochemistry and Cell Biology 46th Meeting of the Polish Biochemical Society and 11st Conference of the Polish Cell Biology Society, Kraków, 2011

17. Piekarska B, Drozd A, Konieczny L et al (2006) The indirect generation of long-distance structural changes in antibodies upon their binding to antigen. Chem Biol Drug Des 68(5):276-283

18. Rybarska J, Piekarska B, Stopa B et al (1984) In vivo accumulation of self-assembling dye Congo red in an area marked by specific immune complexes: possible relevance to chemotherapy. Folia HistochemCytobiol 42(2):101-110

19. Spólnik P, Stopa B, Piekarska B et al (2007) The use of Rigid, Fibrillar Congo red nanostructures for scaffolding protein assemblies and inducing the formation of amyloid-like arrangement of molecules. Chem Biol Drug Des 70(6):491-501

20. Roterman I, Rybarska J, Konieczny L et al (1998) Congo red bound to $\alpha$-1-proteinase inhibitor as a model of supramolecular ligand and protein complex. Comput Chem 22(1):61-70

21. Arnold JW, Shimkets LJ (1988) Inhibition of cell-cell interactions in Myxococcus xanthus by congo red. J Bacteriol 170(12):5765-5770

22. Qadri F, Hossain SA, Ciznár I et al (1988) Congo red binding and salt aggregation as indicators of virulence in Shigella species. J. Clin Microbiol 26(7):1343-1348

23. Ishiguro EE, Ainsworth T, Trust TJ et al (1985) Congo red agar, a differential medium for Aeromonas salmonicida, detects the presence of the cell surface protein array involved in virulence. J. Bacteriol 164(3):1233-1237

24. Chłopaś K, Jagusiak A, Konieczny L et al (2015) The use of Titan yellow dye as a metal ion binding marker for studies on the formation of specific complexes by supramolecular Congo red. Bio-Algorithms Med-Syst 11(1):9-17

25. Rybarska J, Konieczny L, Jagusiak A et al (2017) Silver ions as EM marker of congo red ligation sites in amyloids and amyloid-like aggregates. Acta Biochim Pol 64:161-169

26. Stopa B, Piekarska B, Konieczny L et al (2003) The structure and protein binding of amyloidspecific dye reagents. Acta Biochim Pol 50(4):1213-1227

27. Zhao G, Stevens SE Jr (1998) Multiple parameters for the comprehensive evaluation of the susceptibility of Escherichia coli to the silver ion. Biometals 11(1):27-32

28. Lemire JA, Kalan L, Bradu A et al (2015) Silver oxynitrate, an unexplored silver compound with antimicrobial and antibiofilm activity. Antimicrob Agents Chemother 59(7):4031-4039

29. Hajipour MJ, Fromm KM, Akbar A et al (2012) Antibacterial properties of nanoparticles. Trends Biotechnol 30(10):499-511

30. Kim JS, Kuk E, Yu KN et al (2007) Antimicrobial effects of silver nanoparticles Nanomedicine Nanotechnology. Biol Med 3(1):95-101

31. Gupta A, Phung LT, Taylor DE et al (2017) Diversity of silver resistance genes in IncH incompatibility group plasmids. Microbiology 2046(147):42-3393

32. Matsumura Y, Yoshikata K, Kunisaki S et al (2003) Mode of bactericidal action of silver zeolite and its comparison with that of silver nitrate. Appl. Environ Microbiol 69(7):4278-4281

33. Schierholz JM, Lucas LJ, Rump A, Pulverer G (1998) Efficacy of silver-coated medical devi ces. J Hosp Infect 40(4):257-262 
34. Russell AD, Hugo WB (1994) Antimicrobial Activity and Action of Silver. Prog Med Chem 31:351-370

35. Liau SY, Read DC, Pugh WJ et al (1997) Interaction of silver nitrate with readily identifiable groups: relationship to the antibacterialaction of silver ions Lett. Appl Microbiol 25(4):279-283

36. Feng QL, Wu J, Chen GQ et al (2000) A mechanistic study of the antibacterial effect of silver ions on Escherichia coli and Staphylococcus aureus. J Biomed Mater Res 52:662-668

37. Klasen HJ, Bauer K-H, Gravens DL et al (2000) Historical review of the use of silver in the treatment of burns. I Early uses. Burns 26(2):117-130

38. Silver S (2003) Bacterial silver resistance: molecular biology and uses and misuses of silver compounds. FEMS Microbiol. Rev 27(2-3):341-353

39. Percival SL, Bowler PG, Russell D et al (2005) Bacterial resistance to silver in wound care. J Hosp Infect 60(1):1-7

40. Ruutu M, Alfthan O, Talja M et al (1985) Cytotoxicity of latex urinary catheters. Br J Urol $57(1): 82-87$

Open Access This chapter is distributed under the terms of the Creative Commons Attribution 4.0 International License (http://creativecommons.org/licenses/by/4.0/), which permits use, duplication, adaptation, distribution and reproduction in any medium or format, as long as you give appropriate credit to the original author(s) and the source, provide a link to the Creative Commons license and indicate if changes were made.

The images or other third party material in this chapter are included in the work's Creative Commons license, unless indicated otherwise in the credit line; if such material is not included in the work's Creative Commons license and the respective action is not permitted by statutory regulation, users will need to obtain permission from the license holder to duplicate, adapt or reproduce the material. 